\title{
Sleep apnoea syndrome in 2011: current concepts and future directions
}

\author{
P. Lévy, R. Tamisier, C. Minville, S. Launois and J-L. Pépin
}

I $\mathrm{n}$ the past two decades, obstructive sleep apnoea (OSA) has been identified as a common clinical condition. Epidemiological studies have confirmed a high prevalence of the disease in middle-aged adults. Upper airway collapse occurring during sleep in OSA is still not fully understood but new directions, such as pharyngeal neuropathy and fluid shift towards the neck, have been reported, in addition to obesity and craniofacial changes. OSA is associated with significant excessive daytime sleepiness and cognitive impairment, as well as marked cardiovascular and metabolic morbidities, leading to a significant increase in mortality. Sympathetic activation, oxidative stress and systemic inflammation have been shown to be the main intermediary mechanisms associated with sleep apnoea and intermittent hypoxia. There are now convincing data regarding the association between hypertension, arrhythmias, stroke, coronary heart disease, increased cardiovascular mortality and OSA. Data in OSA models and animal models are now available that support the link between sleep apnoea and atherosclerosis and dysmetabolism. Whether treating sleep apnoea enables chronic cardiovascular and metabolic consequences in OSA to be reversed remains to be established in adequately designed studies, particularly in comparison with usual treatment strategies. In addition, large randomised controlled trials are currently being conducted that will enable a rationale for treatment in various subsets of patients to be established, taking into account age, sex and comorbidities. Also, specific conditions, such as central sleep apnoea (CSA) associated with left ventricular failure and obesity hypoventilation syndrome, have been studied more actively in recent years with regard to pathophysiology and treatment. There is a need to pay closer clinical attention to these conditions and to set up adequate clinical trials.

OSA syndrome corresponds to recurrent episodes of partial or complete pharyngeal collapse during sleep. It is a growing

INSERM unit 1042, Hypoxia PathoPhysiology (HP2) Laboratory, Joseph Fourier University, and EFCR, Locomotion, Rehabilitation and Physiology Dept, Grenoble University Hospital, Grenoble, France.

CORRESPONDENCE: P. Lévy, EFCR, Locomotion, Rehabilitation and Physiology Dept, Grenoble University Hospital, 38043 Grenoble Cedex 09, France. E-mail: PLevy@chu-grenoble.fr

Received: March 17 2011; Accepted after revision: June 202011

PROVENANCE: Submitted article, peer reviewed. health concern affecting up to $5 \%$ of middle-aged males and females in the general population [1].

Upper airway collapse is multifactorial. Upper airway size, which is significantly affected by obesity and craniofacial changes, is known to play a major role. Nevertheless, the upper airway increase in collapsibility and the inadequate neuromuscular response, both of which occur during sleep in OSA patients, remain largely unexplained [2]. There are, however, new promising research directions that have been explored in recent years, i.e. pharyngeal neuropathy $[3,4]$, ventilatory instability [5] and fluid shift towards the pharynx [6, 7].

OSA is a serious health hazard that is now recognised as an independent risk factor for hypertension, arrhythmias, stroke and coronary heart disease [8-11]. A peak in sudden death during the night and an increased rate of cardiovascular morbidity and mortality has been observed in patients with OSA [8, 9]. Sleep apnoea is also associated with several cardiovascular sub-clinical or clinical conditions including diastolic hypertension [12], diastolic ventricular dysfunction $[13,14]$ and early atherosclerosis [15], as well as conditions leading to long-term cardiac pacing [16].

OSA comprises of different types of respiratory events that occur during sleep. According to the severity of the upper airway obstruction, the obstructive events may lead to various stimuli, such as oxygen and carbon dioxide cyclical changes, progressive negative intra-thoracic pressure changes during the obstructive event, and arousal terminating the obstructive event. However, the desaturation-reoxygenation sequence is a typical pattern that is coupled with a majority of respiratory events and thought to be responsible for most of the associated cardiovascular morbidity. This sequence leads to oxidative stress and the production of reactive oxygen species (ROS) [17]. Numerous studies have reported increased oxidative stress using various biological markers, although comorbidities such as diabetes, hypertension or obesity may account for part of these results [17-21]. The increased levels of ROS contribute to generation of adhesion molecules [22, 23], activation of leukocytes [24, 25] and production of vascular and systemic inflammation [26-28]. All these mechanisms are presumably responsible for vascular endothelium damage. They have been extensively studied in intermittent hypoxia model in rodents [29] and more recently in normal volunteers [30, 31].

OSA outcomes have been extensively studied in the past decade and well-controlled studies have been published since 1999 . 
Sleepiness, attention deficits, blood pressure and metabolic changes have been assessed in randomised controlled trials. On-going studies are currently being performed in the USA, Spain [32,33], Australia and China as part of the SAVE (Sleep Apnoea Cardiovascular Endpoints) trial. This trial will provide additional information to longitudinal cohort studies [34] or short-term intervention studies $[35,36]$. Although there is growing evidence that continuous positive airway pressure (CPAP) is effective regarding sleepiness, daytime functioning and blood pressure, it is also clear that most OSA chronic consequences may not be fully reversed by CPAP alone. Residual sleepiness may persist despite CPAP treatment [37, 38], although longer CPAP use may be required [37]. Blood pressure may not be fully controlled with CPAP [39]. CPAP induced metabolic changes seem to be limited, at least in obese subjects [40, 41]. Combined therapy associating CPAP and drugs targeting oxidative stress or inflammation should be further validated. Oral appliances have been extensively studied and used in clinical practice in the past decade. The effectiveness on symptoms in mild-to-moderate OSA appears to be comparable to CPAP $[42,43]$. Oral appliance effects on cardiovascular and metabolic outcomes remain to be studied further. Other treatments remain to be developed, such as drugs targeting upper airway muscle activity and hypoglossal nerve stimulation. In the context of epidemic obesity, weight loss using either very low energy diet or bariatric surgery should be considered in obese subjects [44, 45].

\section{UPPER AIRWAY COLLAPSE}

Upper airway collapse is characteristic of OSA [46]. The overall mechanisms may be summarised as follows: "upper airway collapse is initiated because the wakeful state provides compensatory neuronal activation of dilator muscles in an anatomically compromised collapsible pharynx; accordingly, when this activation is lost at sleep onset, the airway narrows and/or collapses" [47]. Pharyngeal collapse occurrence is, therefore, multifactorial, including reduction in upper airway volume [48], increase in pharyngeal collapsibility [49], changes in upper airway resistance during sleep occurring both during inspiration and expiration [50,51], changes in pharyngeal muscle activity [52-55] and alteration in upper airway protective reflex [4], possibly resulting from denervation induced by prolonged heavy snoring and associated vibratory lesions of the pharynx [3].

The critical closing pressure $\left(P_{\text {crit }}\right)$ of the passive airway is defined as the pressure inside the airway at which the airway collapses. This defines collapsibility and has been studied for $>20$ yrs in OSA. In the past, pharyngeal collapsibility has been studied and correlated with respiratory stability in OSA patients [5]. The tendency toward instability depends on the respiratory control system's "loop gain," a term which defines the "gain" of the negative-feedback loop which regulates ventilation in response to a ventilatory disturbance [56]. If the magnitude of the increase in ventilation is greater than or equal to the magnitude of the preceding apnoea or hypopnoea, i.e. a high loop gain, then the system is highly unstable and will fluctuate between under- and over-ventilation [47]. Loop gain can be measured by sequentially increasing proportional assist ventilation until periodic breathing develops. In a study where $P$ crit was negative $\left(<-1 \mathrm{cmH}_{2} \mathrm{O}\right)$, atmospheric -1 to $+1 \mathrm{cmH}_{2} \mathrm{O}$ or positive $\left(>1 \mathrm{cmH}_{2} \mathrm{O}\right)$, a significant correlation was found between loop gain and apnoea/hypopnoea index (AHI) but only in the atmospheric group. Thus, it seems that ventilatory stability has a substantial impact on apnoea frequency in certain patients with sleep apnoea, particularly those with a pharyngeal closing pressure near atmospheric [5].

Obesity is present in $\sim 40 \%$ of OSA patients. The impact of body weight on OSA [44,57-59] is unlikely to be explained only by mechanical factors. The biological factors linking upper airway patency and obesity remain largely unknown although leptin and leptin resistance may play a role. Leptin and other pro-inflammatory cytokines may potentially contribute to the local inflammatory response reported in the upper airway tissues of OSA patients [3, 60]. Overall, the concept that adipocyte-derived circulating factors can impact on respiratory control of the upper airway or act on the upper airway directly to contribute to the pathogenesis of OSA is intriguing, but currently lacking clear supporting data [47].

Among the new research areas, pharyngeal neuropathy $[3,4]$ is promising. There is evidence that pharyngeal nerve alterations can occur in OSA [61]. We have also evidenced that sleep apnoea may occur in the absence of any favouring factor in the context of neuropathy [62]. In OSA, there is a clear link between inflammation and denervation at the pharyngeal level [3]. This is associated with pharyngeal sensory impairment $[4,63,64]$, which may contribute to upper airway collapse. Whether this is a primary determinant or a secondary consequence in the upper airway collapse remains to be determined and is still a conflicting issue.

Finally, an emerging concept is the role of leg fluid shift in sleep apnoea. A group from Toronto (ON, Canada) hypothesised that leg fluid shift may predispose to upper airway collapse. In the report healthy subjects were randomised to a control period or to application of lower body positive pressure (LBPP) of $40 \mathrm{mmHg}$ via anti-shock trousers to displace fluid from the legs [7]. Application of LBPP caused a significant reduction in leg fluid volume (LFV) and a significant increase in neck circumference. Pharyngeal resistance significantly increased from baseline after 1 and 5 min of LBPP. The authors concluded that these results supported the hypothesis that fluid displacement to the upper body during recumbence may predispose to pharyngeal obstruction during sleep, especially in fluid overload states, such as heart and renal failure [7]. They further evidenced in healthy subjects that displacement of fluid from the legs by LBPP caused distension of the neck and narrowing of the upper airway lumen [65], as well as an increase in upper airway collapsibility [66]. In non-obese OSA the changes in LFV and neck circumference were assessed from the beginning to the end of the night, and during the time spent sitting throughout the previous day [6]. The overnight change in LFV correlated strongly with the AHI, the change in neck circumference and the time spent sitting (fig. 1). Multivariate analysis showed that the only significant independent correlates of the $\mathrm{AHI}$ were overnight changes in LFV and neck circumference, which together explained $68 \%$ of the variability in $\mathrm{AHI}$ among the subjects [6]. In a recent report investigating a small subset of OSA patients, the authors evidenced that wearing compression stockings during the day reduced the AHI by decreasing the 


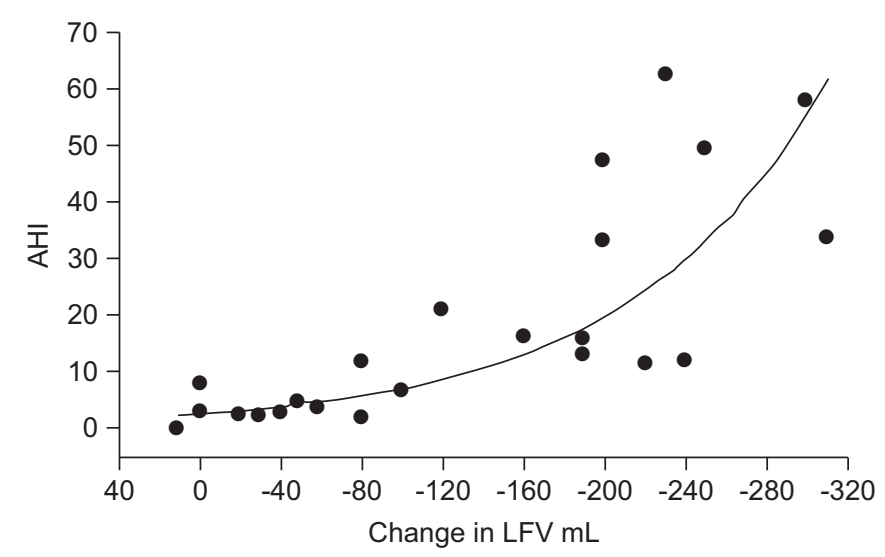

FIGURE 1. Correlation between leg fluid volume (LFV) displacement measured by electrical impedance and apnoea/hypopnoea index (AHI) in non-obese obstructive sleep apnoea. $r=-0.802, p<0.001, n=23$. Reproduced from [6] with permission from the publisher.

amount of fluid available for displacement into the neck overnight by $40 \%$, leading to a median reduction in neck circumference of $42 \%$ [67]. They also evidenced a major contribution of LFV to sleep apnoea in heart failure, with higher fluid displacement overnight in heart failure patients exhibiting CSA-Cheyne-Stokes Respiration (CSA-CSR) [68]. In hypertensive subjects, rostral fluid displacement strongly correlated to the severity of OSA with a greater magnitude in drug-resistant hypertension [69]. There are currently on-going studies investigating therapeutic interventions using diuretics in the afternoon or exercise in order to reduce leg fluid accumulation. Whether LFV shift is such a major contributing factor in sleep apnoea remains to be further studied and confirmed by other research groups.

\section{OSA, INTERMITTENT HYPOXIA AND CARDIOVASCULAR} AND METABOLIC CONSEQUENCES

\section{Intermittent hypoxia, inflammation and oxidative stress}

The desaturation-reoxygenation sequence is a typical pattern coupled with a majority of respiratory events, resulting in intermittent hypoxia. This leads to oxidative stress and the production of ROS [17]. This has been shown using various biological markers although comorbidities such as diabetes, hypertension and obesity per se may contribute [17-20]. Increased ROS levels lead to increased expression of adhesion molecules [22], activation of leukocytes [24] and production of systemic inflammation [70]. Taken together, these mechanisms lead to vascular endothelium damage and dysfunction [71, 72]. Both systemic inflammation and endothelial dysfunction are aggravated when sleep-disordered breathing (SDB) is associated with other comorbid conditions, such as morbid obesity and chronic respiratory failure (i.e. obesity hypoventilation syndrome, OHS) [73] or chronic obstructive pulmonary disease, i.e. overlap syndrome [74]. The role of obesity per se remains highly controversial as in some studies SDB seems to be the only contributing factor of vascular inflammation and dysfunction [75], while obesity has been evidenced as a source of oxidative stress and inflammation [76, 77].

Oxidative stress generates an inflammatory cascade via nuclear factor (NF)- $\kappa \mathrm{B}$ activation [76, 78]. However, inflammatory markers have not been found to be consistently increased in OSA. Obesity and the various associated comorbidities may account for the conflicting results regarding high sensitivity C-reactive protein (CRP) in OSA. Although CRP is found to be increased in several studies [28, 79-81], other reports failed to demonstrate any linear relationship with the severity of OSA [82]. Moreover, a randomised controlled trial [83] did not evidence any significant effect of CPAP, the reference treatment of OSA, on CRP when compared with sham-CPAP, a system delivering very low pressure with no impact on upper airway collapse. Obesity however remains a major confounding factor. A correlation between both leukotrienes (LTs) and urinary isoprostane production was evidenced with vascular remodelling in OSA $[84,85]$. However, urinary LTE $_{4}$, a validated marker of pro-inflammatory cysteinyl LT production, was mainly related with obesity and, to a lesser extent, hypoxia severity (fig. 2) [77].

\section{Intermittent hypoxia animal models: an appropriate model for studying OSA cardiovascular consequence mechanisms}

Animal models have been extensively used in the field. The most frequently used is the chronic intermittent hypoxia model, which mimics the major consequence of OSA [29]. Starting from the early evidence provided by FLETCHER et al. [86] that intermittent hypoxia during night resulted in a daytime increase in blood pressure, there have been many reports on intermittent hypoxia effects, mainly on the cardiovascular system. Vascular reactivity has been shown to be altered in rodents [87-90]. Many biological and pathophysiological changes have been linked to intermittent hypoxia, i.e. alteration in baroreflex activity [91], increase in pulmonary arterial pressure and haematocrit [92], changes in heart structure and function [93], and an alteration in endothelial dependent vasodilation in cerebral and muscular arteries [94]. In addition, an increased response to endothelin (ET)-1 was also demonstrated [89], presumably almost exclusively mediated by ET-A receptors [95]. We recently confirmed the role of the ET-A receptors, overexpressed in the heart during intermittent hypoxia in spontaneously hypertensive rats and responsible for both an increase in blood pressure (BP) and heart sensitivity, to ischaemia [96]. Sensitivity to ischaemia is altered during intermittent hypoxia; it is reduced when intermittent hypoxia is acute, acting as a preconditioning stimulus [97], while increased when intermittent hypoxia is chronic [98]. ET-1 receptors might represent an adequate pharmacological target requiring further testing. An intermittent hypoxia associated increase in BP may involve sympathoadrenergic hyperactivity [99, 100], as well as ET [96, 101] and renin-angiotensin [87], with all of them also being known to be involved in inflammation and vascular remodelling [102].

\section{Intermittent hypoxia, atherosclerosis and elevated BP}

Elevated BP has been shown to be associated with exacerbated chemoreflex whereas baroreflex, which is protective for the vascular wall, was decreased [100]. Interestingly, in intermittent hypoxia mice with BP elevation and baroreflex attenuation, a decreased immunostaining of the endothelial cell marker platelet endothelial cell adhesion molecule- 1 was found, with a topographic distribution pattern in the heart and thoracic aorta that was highly suggestive of haemodynamic strains [100]. 

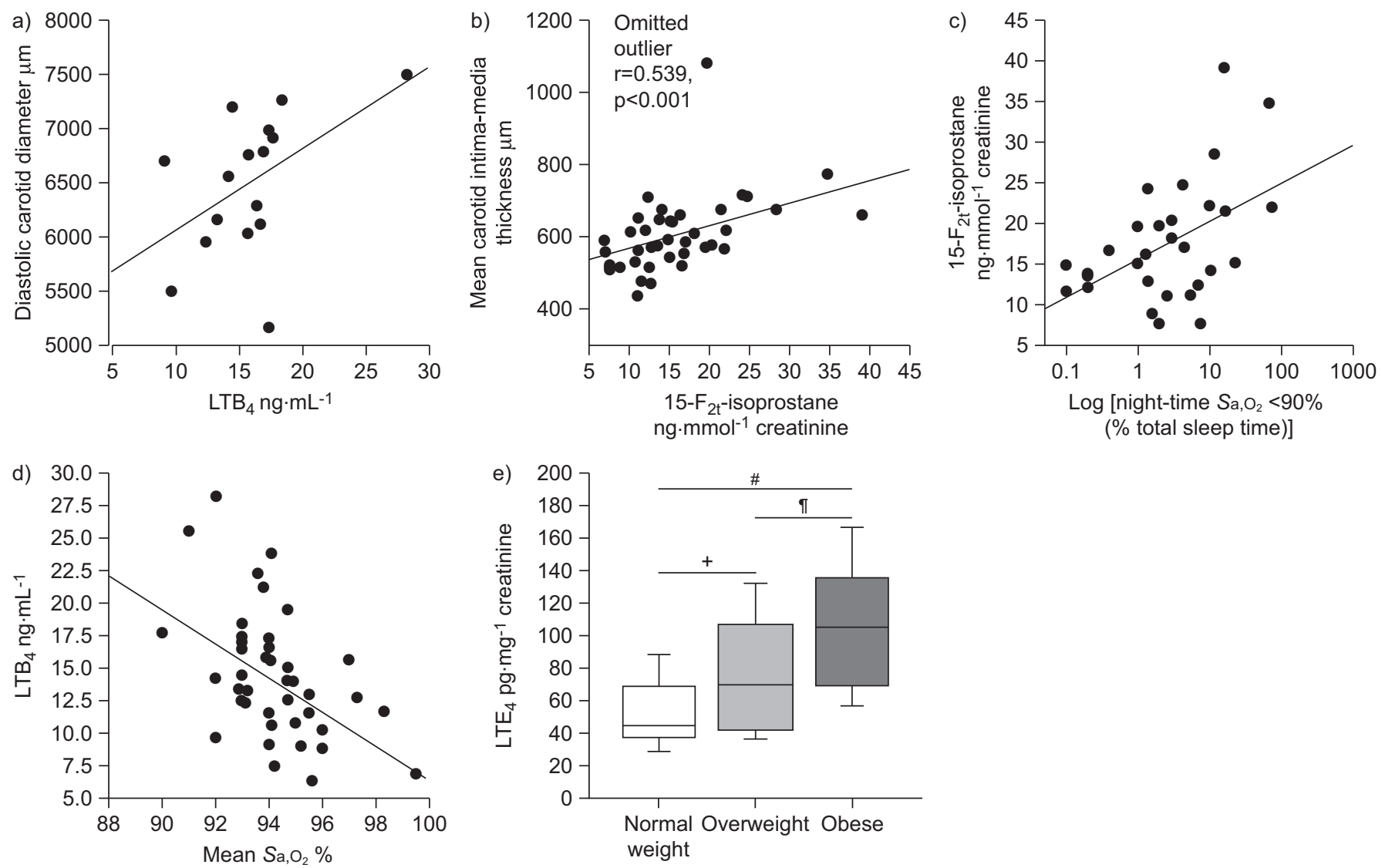

FIGURE 2. a) Correlation between leukotriene ( $L T) B_{4}$ and carotid luminal diameter in vascular remodelling in obstructive sleep apnoea (OSA). b) Correlation between urinary isoprostanes, a marker of oxidative stress, and intima media thickness in vascular remodelling in OSA. $r=0.532, p<0.001$. c) Correlation between isoprostanes and severity of OSA, i.e. cumulative time spent at $<90 \%$ arterial oxygen saturation $\left(\mathrm{Sa}_{1} \mathrm{O}_{2}\right) . r=0.478, \mathrm{p}=0.002$. d) Inverse correlation between $\mathrm{LTB}_{4}$ and mean $\mathrm{Sa}, \mathrm{O}_{2}$. $r=0.53$, $p<0.001$. e) Influence of body weight on $\mathrm{LTE}_{4} .{ }^{\#}: p<0.0001 ;{ }^{\top}: p=0.18 ;{ }^{+}: p=0.11$. a) Reproduced from [84], b, c) reproduced from [85] and e) reproduced from [77] with permission from the publishers. d) Data from [84].

Systemic inflammation plays a key role in atherogenesis [103, 104]. In vivo and in vitro studies with intermittent hypoxia have demonstrated the activation of the pro-inflammatory transcription factor NF- $\kappa B$ in cardiovascular tissue in mice [105], and a selective dose-dependent NF- $\mathrm{BB}$ activation in a cell-culture model [78]. This intermittent hypoxia-induced NF- $\kappa$ B activation could target the increased pro-inflammatory NF- $\kappa B$-dependent genes, such as adhesion molecules (soluble intracellular adhesion molecule- 1 and soluble vascular adhesion molecule) that have been reported as activated in OSA patients [23, 25, 106]. Indeed, a very short-term exposure of only $3 \mathrm{~h}$ to experimentally induced obstructive apnoeas in rats can lead to increased leukocyte rolling, reflecting leukocyte-endothelial cell interaction and expression of P-selectin in colonic veinules [107]. We recently found that intermittent hypoxia led to early systemic and vascular inflammatory alterations including splenic T-cell activation, chemokine expression and increased expression of adhesion molecules in small and large arteries, as well as structural remodelling [108].

\section{OSA DIAGNOSIS}

Traditional OSA diagnosis based on costly and labourintensive polysomnography in a sleep laboratory limits patient's access to diagnosis and treatment $[109,110]$. With growing demands and waiting lists in most sleep centres, new diagnostic tools and screening strategies are required.

Commercially available and relatively inexpensive portable monitors [111, 112] might facilitate earlier recognition of disease and faster initiation of treatment, thereby reducing the healthcare burden associated with OSA. However, highquality clinical trials are needed to compare home versus inlaboratory testing in terms of treatment outcomes in diverse patient populations, to evaluate their cost-effectiveness and to construct appropriate decision-analysis models [113].

Otherwise, regarding screening, an interesting and promising strategy has been studied in a paediatric population where a proteomic approach revealed that OSA was associated with specific and consistent alterations in urinary concentrations of specific protein clusters [114]. Future studies aimed at validating this approach as a screening method of snoring children and adults are warranted.

\section{OSA CONSEQUENCES AND TREATMENT}

Cardiovascular morbidity and mortality associated with sleep apnoea has been extensively studied in the last decade. Data supporting an association between sleep apnoea and hypertension, stroke, arrhythmias, coronary heart disease, as well 
as overall cardiovascular mortality, have been previously reported [34, 115, 116]. The mechanisms supporting this relationship are essentially those that have been previously described regarding intermittent hypoxia in animal or cellular models [117, 118].

Hypertension can be caused by OSA, as is now recognised in international guidelines $[119,120]$. Although not fully understood, the role of hypoxia in promoting an increase in BP seems prominent, as evidenced both in animal models [121] and more recently in a model that was developed in normal volunteers $[30,31]$. In this particular model, it is noticeable that intermittent hypoxia during the night does not produce an immediate increase in $\mathrm{BP}$, presumably due to vasodilation occurring in response to intermittent hypoxia counteracting the effects of sympathetic activation. [31]. However, there is a sustained increase in sympathetic activity that seems to be responsible for the daytime increase in BP that was observed in these subjects after one night of intermittent hypoxia, aggravated after 13 nights and still persistent, although not statistically significant, after 5 days intermittent hypoxia exposure withdrawal (figs 3-5) [31]. BP response to CPAP appears to be dependent on sleep apnoea severity [35, 122, 123]. Whether sleepiness is critical in predicting the CPAP reduction in BP is still under debate [123125], but it is probably unlikely [33]. In any case, the reduction of BP obtained when treating OSA seems relatively limited [33, 123, 126] and far from what has been reported in initial reports [122], even when including only hypertensive patients [33, 126].

Finally, the antihypertensive effect of CPAP and an antihypertensive drug (valsartan) was compared. The CPAP-induced $\mathrm{BP}$ reduction was small $(24 \mathrm{~h}$ mean $\mathrm{BP} 2.1 \pm 4.9 \mathrm{mmHg}$ ) and
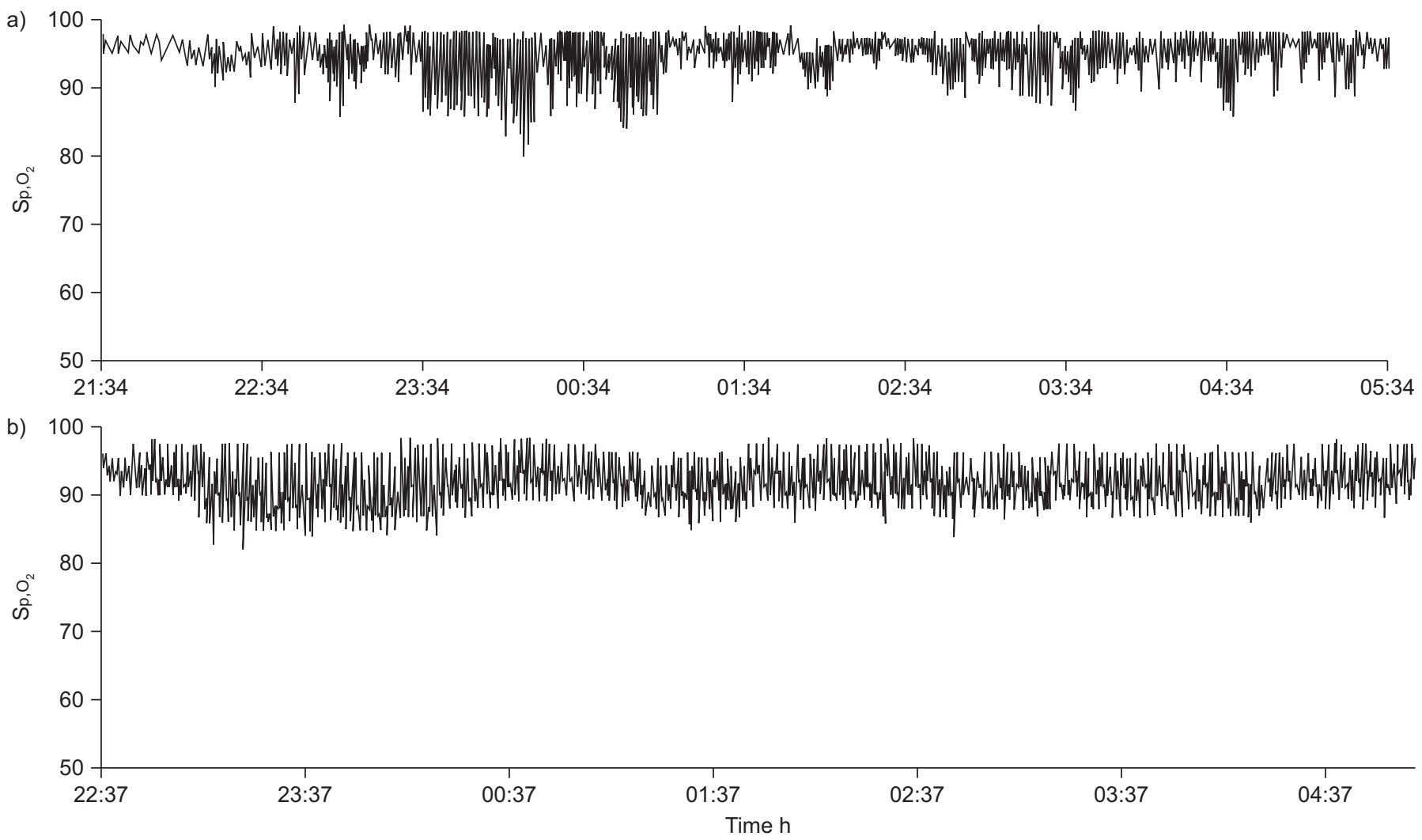

c)

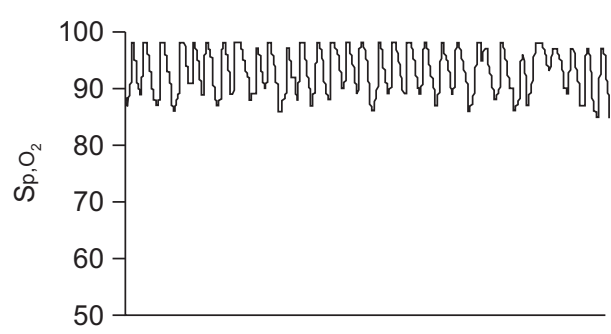

d)

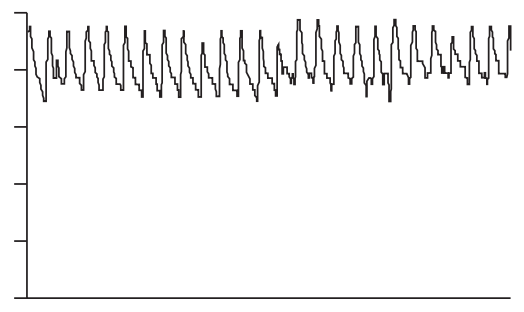

FIGURE 3. The intermittent hypoxia model in normal volunteers. Subjects were exposed to a low inspiratory oxygen fraction (13\%) and were maintained at an arterial oxygen saturation measured by pulse oximetery $\left(\mathrm{Sp}, \mathrm{O}_{2}\right)$ of $92 \%$ using oxygen nasal flow delivery, which was stopped every $120 \mathrm{~s}$ for $20 \mathrm{~s}$. This produced 30 oxygen desaturations per hour. Representive nocturnal oxymetric traces of a) an obstructive sleep apnoea (OSA) patient over $8 \mathrm{~h}, \mathrm{~b}$ ) a healthy subject exposed to intermittent hypoxia for $6 \mathrm{~h}, \mathrm{c}$ ) an OSA patient for 30 mins and d) a healthy subject exposed to intermittent hypoxia for 50 mins. e) The setting for intermittent hypoxia in healthy subjects. 
a)

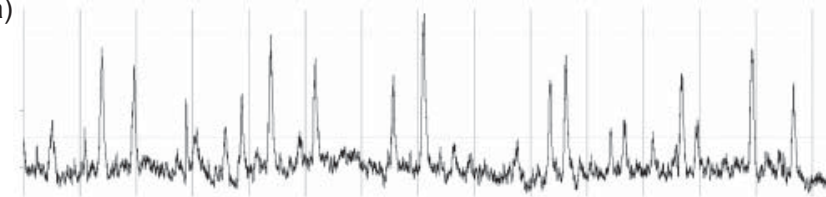

b)
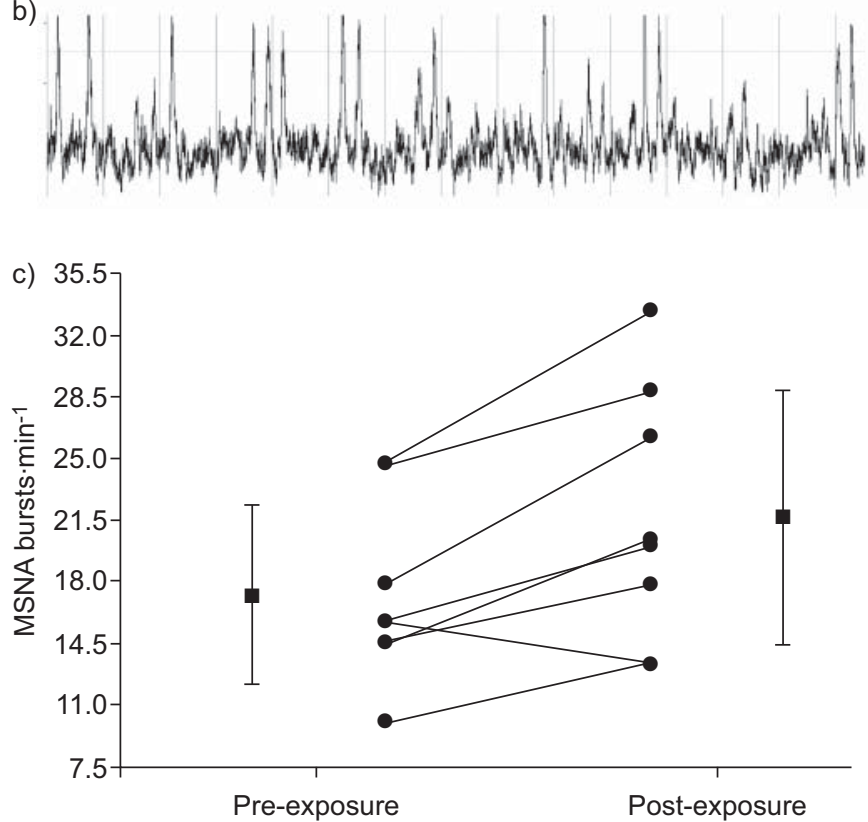

FIGURE 4. Exposure to intermittent hypoxia after 13 nights led to an increase in sympathetic activity measured by muscle sympathetic nerve activity (MSNA) Representive MSNA neurograms from healthy subjects a) before and b) after exposure to intermittent hypoxia. c) Sympathetic activity expressed as MSNA bursts before and after exposure. Reproduced from [31] with permission from the publisher.

significantly lower than that induced by valsartan $(-9.1 \pm 7.2$ $\mathrm{mmHg})$. However, a synergistic effect between CPAP and valsartan was demonstrated [126]. Adequate BP control in hypertensive OSA patients probably needs a treatment with an appropriate antihypertensive drug in addition to CPAP.

\section{Atherosclerosis}

Several reports have established that sleep apnoea, without otherwise significant cardiovascular risk factors, may lead to early atherosclerosis as reflected by increased intima media thickness and occurrence of plaques at the carotid arteries level $[15,127-129]$. In a group of OSA patients without known cardiovascular disease, severity of oxygen desaturation and BP status were the best predictors for carotid wall hypertrophy and occurrence of plaques was also strictly related to the amount of oxygen desaturation [15]. As previously mentioned, vascular remodelling correlated with both sleep apnoea severity and biological markers of atherosclerosis in OSA $[84,85]$. It has been shown that both hypertension and the metabolic syndrome have an additive effect on OSA vascular remodelling [130,131]. This is consistent with sleep apnoea contribution on metabolic dysregulation and systemic inflammation in patients with metabolic syndrome [132]. DRAGER et al. [133] also suggested that CPAP treatment may reverse early atherosclerosis in sleep apnoea.

\section{Metabolic changes}

There have been several studies reporting an independent association of OSA with several components of the metabolic syndrome, particularly insulin resistance and abnormal lipid metabolism [134-136]. This association may further increase cardiovascular risk since the syndrome is recognised to be a risk factor for cardiovascular morbidity and mortality [137, 138]. Recent reports have indicated that the majority of patients with type 2 diabetes also have OSA. Rapidly accumulating data from both epidemiologic and clinical studies [139, 140] suggest that OSA is independently associated with alterations in glucose metabolism and places patients at an increased risk of the development of type 2 diabetes. OSA-related factors that may contribute to metabolic dysregulation include increased sympathetic activity, due to sleep fragmentation and intermittent hypoxia. However, intermittent hypoxia contributes to decrease glucose utilisation of oxidative muscle fibres, independently of autonomic nervous system activation [141]. Intermittent hypoxia also seems to be responsible for increased beta-cell proliferation and cell death, the latter being due to oxidative stress [142]. Intermittent hypoxia results in an increase in serum cholesterol and phospholipids levels, upregulated triglycerides and phospholipids biosynthesis, and inhibited cholesterol uptake in the liver [143]. Finally, liver inflammation and fibrosis appear to result from intermittent or nocturnal hypoxia [144-147].

Even though there is emerging evidence that the relationship between type 2 diabetes and OSA is at least partially independent of adiposity [134, 148], there are several important limitations in the published literature that do not allow us to establish causality i.e. cross-sectional studies, use of snoring as a surrogate marker of OSA, various assessments of glucose metabolism and type 2 diabetes. In addition, CPAP treatment assessment suggests that in obese individuals insulin sensitivity is likely to be determined primarily by obesity and, to a lesser extent, by sleep apnoea [149]. This was confirmed in two randomised controlled trial evaluating metabolic outcomes with therapeutic or sham CPAP in nondiabetic [150] and diabetic patients [151]. In both studies, there was no change in glucose, lipids, insulin resistance or the proportion of patients with metabolic syndrome in obese subjects. However, there is a recent randomised controlled trial providing conflicting data, at least in the case of moderate obesity, with a significant improvement in insulin sensitivity after 1 week and 12 weeks of CPAP treatment [152]. Sleepiness may be associated with higher insulin resistance and worst metabolic response to CPAP [153], although recent studies found no metabolic difference among sleepy and non-sleepy OSA patients $[132,154]$.

\section{CPAP treatment: duration of treatment}

A major issue is the optimal duration for CPAP use [155]. There is little data to establish a clear threshold. However, it seems that excessive daytime sleepiness and daytime functioning including cognitive functioning improvements are dependent upon CPAP duration [37]. In this particular study, thresholds above which further improvements were less likely relative to nightly duration of CPAP were identified for Epworth Sleepiness Scale score $(4 \mathrm{~h})$, multiple sleep latency test $(6 \mathrm{~h})$, and functional outcomes associated with sleepiness questionnaire $(7.5 \mathrm{~h})$. A linear dose-response relationship 

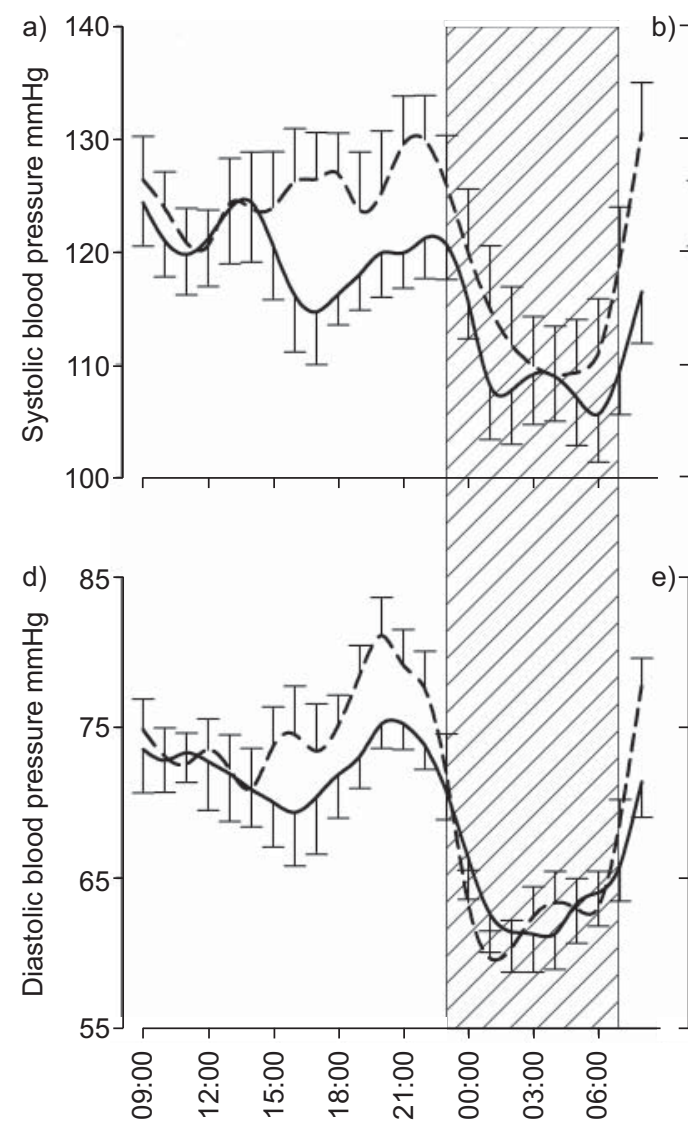

FIGURE 5. 24-h blood pressure profile after a, d) one night of intermittent hypoxia (IH) exposure, b, e) 13 nights $I H$ exposure and c, f) 5 days after cessation of exposure. —-: pre-exposure; ----: post-exposure. $\mathbb{Z}: \mathbb{I H}$. Reproduced from [31] with permission from the publisher.

between increased use and achieving normal levels was shown for objective and subjective daytime sleepiness [37]. Overall, this tends to demonstrate that usual thresholds used in various countries, i.e. 3 or $4 \mathrm{~h}$, are insufficient to suppress OSA consequences. This also appears to be the case with regard to blood pressure. It has been suggested from meta-analysis that the obtained reduction in blood pressure with CPAP is more or less related with increasing use [123]. Moreover, BARBÉ et al. [33] demonstrated that CPAP treatment for $1 \mathrm{yr}$ was associated with a small decrease in BP in non-sleepy OSA patients but only in patients who used CPAP for $>5.6 \mathrm{~h}$ per night [33]. Finally, even with an optimal duration of CPAP use, there is a small subset of patients still presenting with clinically significant residual excessive daytime sleepiness. In a recent multicentre study, this proportion of OSA patients was evaluated at $\sim 6 \%$ [38].

\section{SPECIFIC SDB: CSA IN HEART FAILURE AND OBESITY HYPOVENTILATION}

Congestive heart failure (CHF) in Western societies is a major health issue considering its medical, social and economic consequences [156, 157]. Sleep breathing disorders are common in $\mathrm{CHF}$, and pathophysiologies of both conditions are closely linked. The need to specifically identify and treat such disorders for the improvement of CHF is still under debate, as CSR might represent a marker of CHF severity. CSR with CSA is a breathing disorder seen in $>30 \%$ of patients with advanced CHF [158-160]. One critical and highly discussed question is whether high incidence of CSA persists, despite the newest heart failure treatments, as suggested by the CANPAP study [161]. Since the publication of the CANPAP study, other data has been published that is rather supportive of such a reduction in CSR-CSA prevalence [162], while others found a persistent high prevalence despite a high rate of use of $\beta$ blockers [163, 164]. In any case, severity of heart failure is critical. The diagnosis should be systematically envisaged in severe cardiac failure patients (New York Heart Association stage III-IV and left ventricular ejection fraction (LVEF) $<40 \%$ ). Typically, patients with idiopathic dilated cardiomyopathy are the best candidates. Several factors have been identified as risk factors for SDB namely male sex, age $>40$ yrs, daytime hypocapnia and atrial fibrillation [160]. A recent study evidenced the gap between the need and the reality in the clinical field [165]. JAVAHERI et al. [165] analysed a retrospective cohort study using the 2003 to 2005 Medicare Standard Analytical Files and including subjects with newly diagnosed heart failure from the first quarter of 2004, without prior diagnosis of sleep apnoea, stratified by testing, diagnosis and treatment status. Among a study population of 30,719 incident subjects with heart failure, only 1,263 (4\%) were clinically suspected to have sleep apnoea. Of these, 553 (2\% of the total cohort) received sleep apnoea testing, and 545 
received treatment. Heart failure patients, who were tested, diagnosed and treated for CSA-CSR had a better 2-yr survival rate compared with subjects with heart failure who were not tested. Similarly, among subjects who were tested and diagnosed, those who were treated had a better 2-yr survival rate than those who were not treated [165].

There is convincing evidence that treating CSR-CSA may improve several important surrogate markers, e.g. sympathetic activity, brain natriuretic peptide, LVEF or quality of life [166]. However, it remains unknown whether treating CSR-CSA will improve survival. Since the largest trial, using CPAP provided negative results regarding survival [161], even though a post hoc analysis was more supportive [167], there are now ongoing prospective randomised controlled trials using adaptive servo-ventilation in $\mathrm{CHF}$ patients, e.g. the Serve-HF trial and ADVENT-HF trial.

OHS is also a growing concern, particularly owing to the increase prevalence of obesity. OHS includes both obesity and daytime hypercapnia [168]. There is the possibility of either hypoventilation or apnoeas or both during sleep. These patients actually exhibit an undiagnosed daytime hypercapnia [169]. Use of healthcare resources [170], rates of hospitalisation and early mortality are increased in OHS patients [169]. OHS may represent a very specific model of interaction between adiposity and hypoxia [118]. OHS presents with leptin resistance [171], systemic inflammation and endothelial dysfunction [73]. Thus, leptin may play a central role in OHS pathophysiology with respect to $\mathrm{CO}_{2}$ response [171-176], but also OHS associated morbidity. Leptin may be a modulator of respiratory drive both in obese patients [176] and in OHS patients [175]. Both vigilance [177] and cardiovascular morbidity may be dependent on leptin, as well as on other inflammatory cytokines. One intriguing question is whether adipose tissue hypoxia may occur in OHS and contribute to systemic inflammation [118]. In addition, randomised controlled trials are highly desirable in the field.

\section{SLEEP APNOEA IN ELDERLY PATIENTS}

Healthcare providers are faced with an increasing elderly population and, thus, not surprisingly, sleep apnoea in the elderly has been the focus of numerous studies in the past two decades. Epidemiological studies have demonstrated an increased number of respiratory events during sleep in elderly subjects [178, 179] and sleep apnoea is highly prevalent in subjects aged $>60$ yrs [180]. Questions have been raised about the actual impact of SDB on morbidity and mortality in the elderly and about the necessity to diagnose and treat SDB in this specific population. Untreated SDB in the elderly appears to have a significant impact on mortality, although it remains a conflicting issue. In some studies, sleep apnoea was not found to be associated with an increased mortality rate in older adults [116], while others have demonstrated a survival advantage in moderate apnoea syndrome suggesting, as a potential mechanism, that chronic intermittent hypoxia during sleep may activate adaptive pathways in the elderly [181]. Conversely, other analyses performed in general population cohorts [154] or in selected populations, i.e. institutionalised nursing home females [182], observed an increased mortality rate associated with SDB independently of age. A recent study on a large elderly cohort confirmed an increased mortality due to heart failure and stroke in OSA patients untreated with CPAP compared to CPAP patients. However, no difference was found in ischaemic heart disease mortality [183]. These discrepancies among studies may potentially be explained by the heterogeneity of the patients included in the elderly populations. An age limit is likely to be insufficient to adequately characterise the populations. Other characteristics may be important, as suggested by a recent study demonstrating that the presence of SDB in the setting of excessive daytime sleepiness appears to be a significant mortality risk factor in older adults [184]. Overall, with the remarkable exception of ischaemic heart disease, the typical morbidity associated with sleep apnoea in younger adults is found in the elderly. Regarding treatment, elderly symptomatic SDB patients tolerate CPAP no differently than younger patients, and should be effectively treated [185-188].

In summary, whether sleep apnoea in the elderly represents a specific entity or the same disease as in younger subjects, with some distinctive features, is still unclear. Further research, in particular focusing on the impact of age on sleep apnoea outcomes, is needed.

\section{CONCLUSIONS}

Sleep apnoea, presumably mainly through intermittent hypoxia, is associated with oxidative stress, systemic inflammation, vascular endothelium damage and dysfunction. Both systemic inflammation and endothelial dysfunction are aggravated when SDB is associated with other comorbid conditions, such as morbid obesity. Sleep apnoea is identified as being part of the cluster of chronic metabolic disorders linked to obesity and associated with low-grade inflammation. There are new directions regarding upper airway collapse mechanisms, such as pharyngeal denervation and LFV shift. There is also strong evidence supporting the association between sleep apnoea and hypertension, stroke, arrhythmias and coronary heart disease, as well as overall cardiovascular mortality. CPAP, the most effective treatment of sleep apnoea, may improve cardiovascular outcomes. A reduction in $\mathrm{BP}$ is obtained during CPAP treatment but hypertension treatment may usually require antihypertensive drugs in addition to CPAP. Atherosclerosis and metabolic anomalies are present in OSA even in the absence of any significant comorbidity. However, regression with OSA treatment remains less well established.

\section{STATEMENT OF INTEREST}

None declared.

\section{REFERENCES}

1 Young T, Peppard PE, Gottlieb DJ. Epidemiology of obstructive sleep apnoea: a population health perspective. Am J Respir Crit Care Med 2002; 165: 1217-1239.

2 White DP. Pathogenesis of obstructive and central sleep apnea. Am J Respir Crit Care Med 2005; 172: 1363-1370.

3 Boyd JH, Petrof BJ, Hamid Q, et al. Upper airway muscle inflammation and denervation changes in obstructive sleep apnea. Am J Respir Crit Care Med 2004; 170: 541-546.

4 Dematteis M, Levy $\mathrm{P}$, Pepin JL. A simple procedure for measuring pharyngeal sensitivity: a contribution to the diagnosis of sleep apnoea. Thorax 2005; 60: 418-426. 
5 Wellman A, Jordan AS, Malhotra A, et al. Ventilatory control and airway anatomy in obstructive sleep apnea. Am J Respir Crit Care Med 2004; 170: 1225-1232.

6 Redolfi S, Yumino D, Ruttanaumpawan P, et al. Relationship between overnight rostral fluid shift and obstructive sleep apnea in nonobese men. Am J Respir Crit Care Med 2009; 179: 241-246.

7 Chiu KL, Ryan CM, Shiota S, et al. Fluid shift by lower body positive pressure increases pharyngeal resistance in healthy subjects. Am J Respir Crit Care Med 2006; 174: 1378-1383.

8 Gami AS, Howard DE, Olson EJ, et al. Day-night pattern of sudden death in obstructive sleep apnea. N Engl J Med 2005; 352: 1206-1214.

9 Marin JM, Carrizo SJ, Vicente E, et al. Long-term cardiovascular outcomes in men with obstructive sleep apnoea-hypopnoea with or without treatment with continuous positive airway pressure: an observational study. Lancet 2005; 365: 1046-1053.

10 Arzt M, Young T, Finn L, et al. Association of sleep-disordered breathing and the occurrence of stroke. Am J Respir Crit Care Med 2005; 172: 1447-1451.

11 Mehra R, Benjamin EJ, Shahar E, et al. Association of nocturnal arrhythmias with sleep-disordered breathing: the Sleep Heart Health Study. Am J Respir Crit Care Med 2006; 173: 910-916.

12 Baguet JP, Hammer L, Levy P, et al. Night-time and diastolic hypertension are common and underestimated conditions in newly diagnosed apnoeic patients. J Hypertens 2005; 23: 521-527.

13 Alchanatis M, Tourkohoriti G, Kosmas EN, et al. Evidence for left ventricular dysfunction in patients with obstructive sleep apnoea syndrome. Eur Respir J 2002; 20: 1239-1245.

14 Baguet JP, Barone-Rochette G, Levy P, et al. Left ventricular diastolic dysfunction is linked to severity of obstructive sleep apnoea. Eur Respir J 2010; 36: 1323-1329.

15 Baguet JP, Hammer L, Levy P, et al. The severity of oxygen desaturation is predictive of carotid wall thickening and plaque occurrence. Chest 2005; 128: 3407-3412.

16 Garrigue S, Pepin JL, Defaye P, et al. High prevalence of sleep apnea syndrome in patients with long-term pacing: the European Multicenter Polysomnographic Study. Circulation 2007; 115: 1703-1709.

17 Lavie L. Obstructive sleep apnoea syndrome-an oxidative stress disorder. Sleep Med Rev 2003; 7: 35-51.

18 Lavie L, Vishnevsky A, Lavie P. Evidence for lipid peroxidation in obstructive sleep apnea. Sleep 2004; 27: 123-128.

19 Barcelo A, Miralles C, Barbe F, et al. Abnormal lipid peroxidation in patients with sleep apnoea. Eur Respir J 2000; 16: 644-647.

20 Svatikova A, Wolk R, Lerman LO, et al. Oxidative stress in obstructive sleep apnoea. Eur Heart J 2005; 26: 2435-2439.

21 Barcelo A, Barbe F, de la Pena M, et al. Antioxidant status in patients with sleep apnoea and impact of continuous positive airway pressure treatment. Eur Respir J 2006; 27: 756-760.

22 Ohga E, Tomita $\mathrm{T}$, Wada $\mathrm{H}$, et al. Effects of obstructive sleep apnea on circulating ICAM-1, IL-8, and MCP-1. J Appl Physiol 2003; 94: 179-184.

23 Lavie L, Dyugovskaya L, Lavie P. Sleep-apnea-related intermittent hypoxia and atherogenesis: adhesion molecules and monocytes/endothelial cells interactions. Atherosclerosis 2005; 183: 183-184.

24 Schulz R, Mahmoudi S, Hattar K, et al. Enhanced release of superoxide from polymorphonuclear neutrophils in obstructive sleep apnea. Impact of continuous positive airway pressure therapy. Am J Respir Crit Care Med 2000; 162: 566-570.

25 Dyugovskaya L, Lavie P, Lavie L Increased adhesion molecules expression, production of reactive oxygen species in leukocytes of sleep apnea patients. Am J Respir Crit Care Med 2002; 165: 934-939.

26 Carpagnano GE, Kharitonov SA, Resta O, et al. Increased 8isoprostane and interleukin- 6 in breath condensate of obstructive sleep apnea patients. Chest 2002; 122: 1162-1167.
27 Minoguchi K, Yokoe T, Tanaka A, et al. Association between lipid peroxidation and inflammation in obstructive sleep apnoea. Eur Respir J 2006; 28: 378-385.

28 Shamsuzzaman AS, Winnicki M, Lanfranchi P, et al. Elevated Creactive protein in patients with obstructive sleep apnea Circulation 2002; 105: 2462-2464.

29 Dematteis M, Godin-Ribuot D, Arnaud C, et al. Cardiovascular consequences of sleep-disordered breathing: contribution of animal models to understanding the human disease. ILAR 2009; 50: 262-281.

30 Tamisier R, Gilmartin GS, Launois SH, et al. A new model of chronic intermittent hypoxia in humans: effect on ventilation, sleep, and blood pressure. J Appl Physiol 2009; 107: 17-24.

31 Tamisier R, Pépin JL, Rémy J, et al. 14 nights of intermittent hypoxia elevate daytime blood pressure and sympathetic activity in healthy humans. Eur Respir J 2011; 37: 119-128.

32 Phillips B. Your tax dollars at work! or the APPLES trial bears fruit. J Clin Sleep Med 2008; 4: 419-420.

33 Barbe F, Duran-Cantolla J, Capote F, et al. Long-term effect of continuous positive airway pressure in hypertensive patients with sleep apnea. Am J Respir Crit Care Med 2010; 181: 718-726.

34 Marin JM, Carrizo SJ, Vicente E, et al. Long-term cardiovascular outcomes in men with obstructive sleep apnoea-hypopnoea with or without treatment with continuous positive airway pressure: an observational study. Lancet 2005; 365: 1046-1053.

35 Pepperell JC, Ramdassingh-Dow S, Crosthwaite N, et al. Ambulatory blood pressure after therapeutic and subtherapeutic nasal continuous positive airway pressure for obstructive sleep apnoea: a randomised parallel trial. Lancet 2002; 359: 204-210.

36 Jenkinson C, Davies RJ, Mullins R, et al. Comparison of therapeutic and subtherapeutic nasal continuous positive airway pressure for obstructive sleep apnoea: a randomised prospective parallel trial. Lancet 1999; 353: 2100-2105.

37 Weaver TE, Maislin G, Dinges DF, et al. Relationship between hours of CPAP use and achieving normal levels of sleepiness and daily functioning. Sleep 2007; 30: 711-719.

38 Pepin JL, Viot-Blanc V, Escourrou P, et al. Prevalence of residual excessive sleepiness in CPAP-treated sleep apnoea patients: the French multicentre study. Eur Respir J 2009; 33: 1062-1067.

39 Pepin JL, Tamisier R, Barone-Rochette G, et al. Comparison of continuous positive airway pressure and valsartan in hypertensive sleep apnea patients. Am J Respir Crit Care Med 2010; 182: 954-960.

40 West SD, Nicoll DJ, Wallace TM, et al. Effect of CPAP on insulin resistance and $\mathrm{HbA} 1 \mathrm{c}$ in men with obstructive sleep apnoea and type 2 diabetes. Thorax 2007; 62: 969-974.

41 Sharma SK, Kumpawat S, Goel A, et al. Obesity, and not obstructive sleep apnea, is responsible for metabolic abnormalities in a cohort with sleep-disordered breathing. Sleep Med 2007; 8: $12-17$

42 Lim J, Lasserson TJ, Fleetham J, et al. Oral appliances for obstructive sleep apnoea. Cochrane Database Syst Rev 2006; 1: CD004435.

43 Gagnadoux F, Fleury B, Vielle B, et al. Titrated mandibular advancement versus positive airway pressure for sleep apnoea. Eur Respir J 2009; 34: 914-920.

44 Johansson K, Neovius M, Lagerros YT, et al. Effect of a very low energy diet on moderate and severe obstructive sleep apnoea in obese men: a randomised controlled trial. BMJ 2009; 339: b4609.

45 Greenburg DL, Lettieri CJ, Eliasson AH. Effects of surgical weight loss on measures of obstructive sleep apnea: a metaanalysis. Am J Med 2009; 122: 535-542.

46 Pepin JL, Ferretti G, Veale D, et al. Somnofluoroscopy, computed tomography, and cephalometry in the assessment of the airway in obstructive sleep apnoea. Thorax 1992; 47: 150-156.

47 Dempsey JA, Veasey SC, Morgan BJ, et al. Pathophysiology of sleep apnea. Physiol Rev 2010; 90: 47-112. 
48 Mayer P, Pepin JL, Bettega G, et al. Relationship between body mass index, age and upper airway measurements in snorers and sleep apnoea patients. Eur Respir J 1996; 9: 1801-1809.

49 Schwartz AR, Gold AR, Schubert N, et al. Effect of weight loss on upper airway collapsibility in obstructive sleep apnea. Am Rev Respir Dis 1991; 144: 494-498.

50 Morrell MJ, Arabi Y, Zahn B, et al. Progressive retropalatal narrowing preceding obstructive apnea. Am J Respir Crit Care Med 1998; 158: 1974-1981.

51 Tamisier R, Pepin JL, Wuyam B, et al. Expiratory changes in pressure: flow ratio during sleep in patients with sleepdisordered breathing. Sleep 2004; 27: 240-248.

52 Horner RL. Motor control of the pharyngeal musculature and implications for the pathogenesis of obstructive sleep apnea. Sleep 1996; 19: 827-853.

53 Mezzanotte WS, Tangel DJ, White DP. Waking genioglossal electromyogram in sleep apnea patients versus normal controls (a neuromuscular compensatory mechanism). J Clin Invest 1992; 89: 1571-1579.

54 Berry RB, White DP, Roper J, et al. Awake negative pressure reflex response of the genioglossus in OSA patients and normal subjects. J Appl Physiol 2003; 94: 1875-1882.

55 Carrera M, Barbe F, Sauleda J, et al. Patients with obstructive sleep apnea exhibit genioglossus dysfunction that is normalized after treatment with continuous positive airway pressure. Am J Respir Crit Care Med 1999; 159: 1960-1966.

56 Khoo MC, Kronauer RE, Strohl KP, et al. Factors inducing periodic breathing in humans: a general model. J Appl Physiol 1982; 53: 644-59.

57 Foster GD, Borradaile KE, Sanders MH, et al. A randomized study on the effect of weight loss on obstructive sleep apnea among obese patients with type 2 diabetes: the Sleep AHEAD study. Arch Intern Med 2009; 169: 1619-1626.

58 Peppard PE, Young T, Palta M, et al. Longitudinal study of moderate weight change and sleep-disordered breathing. JAMA 2000; 284: 3015-3021.

59 Young T, Peppard PE, Taheri S. Excess weight and sleepdisordered breathing. J Appl Physiol 2005; 99: 1592-1599.

60 Series F, Chakir J, Boivin D. Influence of weight and sleep apnea status on immunologic and structural features of the uvula. Am J Respir Crit Care Med 2004; 170: 1114-1119.

61 Svanborg E. Upper airway nerve lesions in obstructive sleep apnea. Am J Respir Crit Care Med 2001; 164: 187-189.

62 Dematteis M, Pepin JL, Jeanmart M, et al. Charcot-Marie-tooth disease and sleep apnoea syndrome: a family study. Lancet 2001; 357: 267-272

63 Kimoff RJ, Sforza E, Champagne V, et al. Upper airway sensation in snoring and obstructive sleep apnea. Am J Respir Crit Care Med 2001; 164: 250-255.

64 Jobin V, Champagne V, Beauregard J, et al. Swallowing function and upper airway sensation in obstructive sleep apnea. I Appl Physiol 2007; 102: 1587-1594.

65 Shiota S, Ryan CM, Chiu KL, et al. Alterations in upper airway cross-sectional area in response to lower body positive pressure in healthy subjects. Thorax 2007; 62: 868-872.

66 Su MC, Chiu KL, Ruttanaumpawan P, et al. Lower body positive pressure increases upper airway collapsibility in healthy subjects. Respir Physiol Neurobiol 2008; 161: 306-312.

67 Redolfi S, Arnulf I, Pottier M, et al. Effects of venous compression of the legs on overnight rostral fluid shift and obstructive sleep apnea. Respir Physiol Neurobiol 2011; 175: 390-393.

68 Yumino D, Redolfi S, Ruttanaumpawan P, et al. Nocturnal rostral fluid shift: a unifying concept for the pathogenesis of obstructive and central sleep apnea in men with heart failure. Circulation 2010; 121: 1598-1605.
69 Friedman O, Bradley TD, Chan CT, et al. Relationship between overnight rostral fluid shift and obstructive sleep apnea in drugresistant hypertension. Hypertension 2010; 56: 1077-1082.

70 Garvey JF, Taylor CT, McNicholas WT. Cardiovascular disease in obstructive sleep apnoea syndrome: the role of intermittent hypoxia and inflammation. Eur Respir J 2009; 33: 1195-1205.

71 Nieto FJ, Herrington DM, Redline S, et al. Sleep apnea and markers of vascular endothelial function in a large community sample of older adults. Am I Respir Crit Care Med 2004; 169: 354-360.

72 Itzhaki S, Lavie L, Pillar G, et al. Endothelial dysfunction in obstructive sleep apnea measured by peripheral arterial tone response in the finger to reactive hyperemia. Sleep 2005; 28: 594-600.

73 Borel J-C, Roux-Lombard P, Tamisier R, et al. Endothelial dysfunction and specific inflammation in obesity hypoventilation syndrome. PLOS ONE 2009; 4: e6733.

74 Marin JM, Soriano JB, Carrizo SJ, et al. Outcomes in patients with chronic obstructive pulmonary disease and obstructive sleep apnea: the overlap syndrome. Am J Respir Crit Care Med 2010; 182: 325-331.

75 Jelic S, Lederer DJ, Adams T, et al. Vascular inflammation in obesity and sleep apnea. Circulation 2010; 121: 1014-1021.

76 Pierce GL, Lesniewski LA, Lawson BR, et al. Nuclear factorkappaB activation contributes to vascular endothelial dysfunction via oxidative stress in overweight/obese middle-aged and older humans. Circulation 2009; 119: 1284-1292.

77 Stanke-Labesque F, Back M, Lefebvre B, et al. Increased urinary leukotriene E4 excretion in obstructive sleep apnea: effects of obesity and hypoxia. J Allergy Clin Immunol 2009; 124: 364-370.

78 Ryan S, Taylor CT, McNicholas WT. Selective activation of inflammatory pathways by intermittent hypoxia in obstructive sleep apnea syndrome. Circulation 2005; 112: 2660-2667.

79 Yokoe T, Minoguchi K, Matsuo H, et al. Elevated levels of Creactive protein and interleukin- 6 in patients with obstructive sleep apnea syndrome are decreased by nasal continuous positive airway pressure. Circulation 2003; 107: 1129-1134.

80 Larkin EK, Rosen CL, Kirchner HL, et al. Variation of C-reactive protein levels in adolescents: association with sleep-disordered breathing and sleep duration. Circulation 2005; 111: 1978-1984.

81 Lui MM, Lam JC, Mak HK, et al. C-reactive protein is associated with obstructive sleep apnea independent of visceral obesity. Chest 2009; 135: 950-956.

82 Guilleminault C, Kirisoglu C, Ohayon MM. C-reactive protein and sleep-disordered breathing. Sleep 2004; 27: 1507-1511.

83 Kohler M, Ayers L, Pepperell JCT, et al. Effects of continuous positive airway pressure on systemic inflammation in patients with moderate to severe obstructive sleep apnoea: a randomised controlled trial. Thorax 2009; 64: 67-73.

84 Lefebvre B, Pepin JL, Baguet JP, et al. Leukotriene $\mathrm{B}_{4}$ : early mediator of atherosclerosis in obstructive sleep apnoea? Eur Respir J 2008; 32: 113-120.

85 Monneret D, Pepin J-L, Godin-Ribuot D, et al. Association of urinary 15-F2t-isoprostane level with oxygen desaturation and carotid intima-media thickness in nonobese sleep apnea patients. Free Radic Biol Med 2010; 48: 619-625.

86 Fletcher EC, Lesske J, Qian W, et al. Repetitive, episodic hypoxia causes diurnal elevation of blood pressure in rats. Hypertension 1992; 19: 555-561.

87 Fletcher EC, Bao G, Li R. Renin activity and blood pressure in response to chronic episodic hypoxia. Hypertension 1999; 34: 309-314.

88 Julien C, Bayat S, Levy P. Vascular reactivity to norepinephrine and acetylcholine after chronic intermittent hypoxia in mice. Respir Physiol Neurobiol 2003; 139: 21-32.

89 Lefebvre B, Godin-Ribuot D, Joyeux-Faure M, et al. Functional assessment of vascular reactivity after chronic intermittent hypoxia in the rat. Respir Physiol Neurobiol 2006; 150: 278-286. 
90 Greenberg HE, Sica A, Batson D, et al. Chronic intermittent hypoxia increases sympathetic responsiveness to hypoxia and hypercapnia. J Appl Physiol 1999; 86: 298-305.

91 Brooks D, Horner RL, Floras JS, et al. Baroreflex control of heart rate in a canine model of obstructive sleep apnea. Am J Respir Crit Care Med 1999; 159: 1293-1297.

92 McGuire M, Bradford A. Chronic intermittent hypercapnic hypoxia increases pulmonary arterial pressure and haematocrit in rats. Eur Respir J 2001; 18: 279-285.

93 Kraiczi H, Magga J, Sun XY, et al. Hypoxic pressor response, cardiac size, and natriuretic peptides are modified by long-term intermittent hypoxia. J Appl Physiol 1999; 87: 2025-2031.

94 Phillips SA, Olson EB, Morgan BJ, et al. Chronic intermittent hypoxia impairs endothelium-dependent dilation in rat cerebral and skeletal muscle resistance arteries. Am J Physiol Heart Circ Physiol 2004; 286: H388-H393.

95 Allahdadi KJ, Walker BR, Kanagy NL. Augmented endothelin vasoconstriction in intermittent hypoxia-induced hypertension. Hypertension 2005; 45: 705-709.

96 Belaidi E, Joyeux-Faure $\mathrm{M}$, Ribuot $\mathrm{C}$, et al. Major role for hypoxia inducible factor- 1 and the endothelin system in promoting myocardial infarction and hypertension in an animal model of obstructive sleep apnea. J Am Coll Cardiol 2009; 53: 1309-1317.

97 Beguin PC, Joyeux-Faure M, Godin-Ribuot D, et al. Acute intermittent hypoxia improves rat myocardium tolerance to ischemia. J Appl Physiol 2005; 99: 1064-1069.

98 Joyeux-Faure M, Stanke-Labesque F, Lefebvre B, et al. Chronic intermittent hypoxia increases infarction in the isolated rat heart. J Appl Physiol 2005; 98: 1691-1696.

99 Fletcher EC. Effect of episodic hypoxia on sympathetic activity and blood pressure. Respir Physiol 2000; 119: 189-197.

100 Dematteis M, Julien C, Guillermet C, et al. Intermittent hypoxia induces early functional cardiovascular remodeling in mice. Am J Respir Crit Care Med 2008; 177: 227-235.

101 Kanagy NL, Walker BR, Nelin LD. Role of endothelin in intermittent hypoxia-induced hypertension. Hypertension 2001; 37: 511-515.

102 Morgan BJ. Vascular consequences of intermittent hypoxia. Adv Exp Med Biol 2007; 618: 69-84.

103 Hansson GK. Inflammation, atherosclerosis, and coronary artery disease. N Engl J Med 2005; 352: 1685-1695.

104 Foster GE, Poulin MJ, Hanly PJ. Intermittent hypoxia and vascular function: implications for obstructive sleep apnoea. Exp Physiol 2007; 92: 51-65.

105 Greenberg H, Ye X, Wilson D, et al. Chronic intermittent hypoxia activates nuclear factor-kappaB in cardiovascular tissues in vivo. Biochem Biophys Res Commun 2006; 343: 591-596.

106 Ohga E, Nagase T, Tomita T, et al. Increased levels of circulating ICAM-1, VCAM-1, and L-selectin in obstructive sleep apnea syndrome. J Appl Physiol 1999; 87: 10-14.

107 Nacher M, Serrano-Mollar A, Farre R, et al. Recurrent obstructive apneas trigger early systemic inflammation in a rat model of sleep apnea. Respir Physiol Neurobiol 2007; 155: 93-96.

108 Arnaud C, Beguin P, Lantuejoul S, et al. The inflammatory preatherosclerotic remodeling induced by intermittent hypoxia is attenuated by RANTES/CCL5 inhibition. Am J Respir Crit Care Med 2011 [Epub ahead of print DOI: 10.1164/rccm.2010122033OC].

109 Flemons WW, Douglas NJ, Kuna ST, et al. Access to diagnosis and treatment of patients with suspected sleep apnea. Am J Respir Crit Care Med 2004; 169: 668-672.

110 Pack AI. Sleep-disordered breathing: access is the issue. Am J Respir Crit Care Med 2004; 169: 666-667.

111 Collop NA, Anderson WM, Boehlecke B, et al. Clinical guidelines for the use of unattended portable monitors in the diagnosis of obstructive sleep apnea in adult patients. Portable Monitoring
Task Force of the American Academy of Sleep Medicine. J Clin Sleep Med 2007; 3: 737-747.

112 Flemons WW, Littner MR, Rowley JA, et al. Home diagnosis of sleep apnea: a systematic review of the literature. An evidence review cosponsored by the American Academy of Sleep Medicine, the American College of Chest Physicians, and the American Thoracic Society. Chest 2003; 124: 1543-1579.

113 Kuna ST, Badr MS, Kimoff RJ, et al. An official ATS/AASM/ $\mathrm{ACCP} / \mathrm{ERS}$ workshop report: research priorities in ambulatory management of adults with obstructive sleep apnea. Proc Am Thorac Soc 2011; 8: 1-16.

114 Gozal D, Jortani S, Snow AB, et al. Two-dimensional differential in-gel electrophoresis proteomic approaches reveal urine candidate biomarkers in paediatric obstructive sleep apnea. Am J Respir Crit Care Med 2009; 180: 1253-1261.

115 McNicholas WT, Bonsignore MR, COST action B26 MC. Sleep apnoea as an independent risk factor for cardiovascular disease: current evidence, basic mechanisms and research priorities. Eur Respir J 2007; 29: 156-178.

116 Punjabi NM, Caffo BS, Goodwin JL, et al. Sleep-disordered breathing and mortality: a prospective cohort study. PLoS Med 2009; 6: e1000132.

117 Neubauer JA. Invited review: physiological and pathophysiological responses to intermittent hypoxia. J Appl Physiol 2001; 90 1593-1599.

118 Levy P, Pepin JL, Arnaud C, et al. Intermittent hypoxia and sleep-disordered breathing: current concepts and perspectives. Eur Respir J 2008; 32: 1082-1095.

119 Baguet JP, Narkiewicz K, Mallion JM. Update on hypertension management: obstructive sleep apnea and hypertension. J Hypertens 2006; 24: 205-208.

120 Chobanian AV, Bakris GL, Black HR, et al. The Seventh Report of the Joint National Committee on Prevention, Detection, Evaluation, and Treatment of High Blood Pressure: the JNC 7 report. JAMA 2003; 289: 2560-2572.

121 Brooks D, Horner RL, Kimoff RJ, et al. Effect of obstructive sleep apnea versus sleep fragmentation on responses to airway occlusion. Am J Respir Crit Care Med 1997; 155: 1609-1617.

122 Becker HF, Jerrentrup A, Ploch T, et al. Effect of nasal continuous positive airway pressure treatment on blood pressure in patients with obstructive sleep apnea. Circulation 2003; 107: 68-73.

123 Haentjens P, Van Meerhaeghe A, Moscariello A, et al. The impact of continuous positive airway pressure on blood pressure in patients with obstructive sleep apnea syndrome: evidence from a meta-analysis of placebo-controlled randomized trials. Arch Intern Med 2007; 167: 757-764.

124 Barbe F, Mayoralas LR, Duran J, et al. Treatment with continuous positive airway pressure is not effective in patients with sleep apnea but no daytime sleepiness: a randomized, controlled trial. Ann Intern Med 2001; 134: 1015-1023.

125 Robinson GV, Smith DM, Langford BA, et al. Continuous positive airway pressure does not reduce blood pressure in nonsleepy hypertensive OSA patients. Eur Respir J 2006; 27: 1229-1235.

126 Pepin J-L, Tamisier R, Barone-Rochette G, et al. Comparison of continuous positive airway pressure and valsartan in hypertensive patients with sleep apnea. Am J Respir Crit Care Med 2010; 182: 954-960.

127 Lévy P, Pepin JL, Arnaud C, et al. Obstructive sleep apnea and atherosclerosis. Prog Cardiovasc Dis 2009; 51: 400-410.

128 Minoguchi K, Yokoe T, Tazaki T, et al. Increased carotid intimamedia thickness and serum inflammatory markers in obstructive sleep apnea. Am J Respir Crit Care Med 2005; 172: 625-630.

129 Drager LF, Bortolotto LA, Lorenzi MC, et al. Early signs of atherosclerosis in obstructive sleep apnea. Am J Respir Crit Care Med 2005; 172: 613-618. 
130 Drager LF, Bortolotto LA, Krieger EM, et al. Additive effects of obstructive sleep apnea and hypertension on early markers of carotid atherosclerosis. Hypertension 2009; 53: 64-69.

131 Drager LF, Bortolotto LA, Maki-Nunes C, et al. The incremental role of obstructive sleep apnoea on markers of atherosclerosis in patients with metabolic syndrome. Atherosclerosis 2010; 208: 490-495.

132 Drager LF, Lopes HF, Maki-Nunes C, et al. The impact of obstructive sleep apnea on metabolic and inflammatory markers in consecutive patients with metabolic syndrome. PLoS One 2010; 5: e12065.

133 Drager LF, Bortolotto LA, Figueiredo AC, et al. Effects of CPAP on early signs of atherosclerosis in obstructive sleep apnea. Am Respir Crit Care Med 2007; 176: 706-712.

134 Lévy P, Bonsignore MR, Eckel J. Sleep, sleep-disordered breathing and metabolic consequences. Eur Respir J 2009; 34: 243-260.

135 Tasali E, Ip MS. Obstructive sleep apnea and metabolic syndrome: alterations in glucose metabolism and inflammation. Proc Am Thorac Soc 2008; 5: 207-217.

136 Coughlin SR, Mawdsley L, Mugarza JA, et al. Obstructive sleep apnoea is independently associated with an increased prevalence of metabolic syndrome. Eur Heart J 2004; 25: 735-741.

137 Ford ES. Risks for all-cause mortality, cardiovascular disease, and diabetes associated with the metabolic syndrome: a summary of the evidence. Diabetes Care 2005; 28: 1769-1778.

138 Sundstrom J, Riserus U, Byberg L, et al. Clinical value of the metabolic syndrome for long term prediction of total and cardiovascular mortality: prospective, population based cohort study. BMJ 2006; 332: 878-882.

139 Tasali E, Mokhlesi B, Van Cauter E. Obstructive sleep apnea and type 2 diabetes: interacting epidemics. Chest 2008; 133 496-506.

140 Shaw JE, Punjabi NM, Wilding JP, et al. Sleep-disordered breathing and type 2 diabetes: a report from the International Diabetes Federation Taskforce on Epidemiology and Prevention. Diabetes Res Clin Pract 2008; 81: 2-12.

141 Iiyori N, Alonso LC, Li J, et al. Intermittent hypoxia causes insulin resistance in lean mice independent of autonomic activity. Am J Respir Crit Care Med 2007; 175: 851-857.

$142 \mathrm{Xu}$ J, Long YS, Gozal D, et al. Beta-cell death and proliferation after intermittent hypoxia: role of oxidative stress. Free Radic Biol Med 2009; 46: 783-790.

$143 \mathrm{Li} \mathrm{J}$, Thorne LN, Punjabi NM, et al. Intermittent hypoxia induces hyperlipidemia in lean mice. Circ Res 2005; 97: 698-706.

144 Savransky V, Nanayakkara A, Vivero A, et al. Chronic intermittent hypoxia predisposes to liver injury. Hepatology 2007; 45: 1007-1013.

145 Savransky V, Bevans S, Nanayakkara A, et al. Chronic intermittent hypoxia causes hepatitis in a mouse model of diet-induced fatty liver. Am J Physiol Gastrointest Liver Physiol 2007; 293: G871-G877.

146 Tanne F, Gagnadoux F, Chazouilleres O, et al. Chronic liver injury during obstructive sleep apnea. Hepatology 2005; 41: 1290-1296.

147 Aron Wisnewski J, Minville C, Trodjman J, et al. Chronic intermittent hypoxia is a major trigger for non-alcoholic fatty liver disease in morbid obese. J Hepatology 2011 [Epub ahead of print DOI 10.1016/j.jhep.2011.04.022].

148 West SD, Nicoll DJ, Stradling JR. Prevalence of obstructive sleep apnoea in men with type 2 diabetes. Thorax 2006; 61: 945-950.

149 Harsch IA, Schahin SP, Radespiel-Troger M, et al. Continuous positive airway pressure treatment rapidly improves insulin sensitivity in patients with obstructive sleep apnea syndrome. Am J Respir Crit Care Med 2004; 169: 156-162.

150 Coughlin SR, Mawdsley L, Mugarza JA, et al. Cardiovascular and metabolic effects of CPAP in obese males with OSA. Eur Respir J 2007; 29: 720-727.

151 West SD, Nicoll DJ, Wallace TM, et al. The effect of CPAP on insulin resistance and $\mathrm{HbA} 1 \mathrm{c}$ in men with obstructive sleep apnoea and type 2 diabetes. Thorax 2007; 62: 969-974.
152 Lam JC, Lam B, Yao TJ, et al. A randomised controlled trial of nasal continuous positive airway pressure on insulin sensitivity in obstructive sleep apnoea. Eur Respir J 2010; 35: 138-145.

153 Barcelo A, Barbe F, de la Pena M, et al. Insulin resistance and daytime sleepiness in patients with sleep apnoea. Thorax 2008; 63: 946-950.

154 Young T, Finn L, Peppard PE, et al. Sleep disordered breathing and mortality: eighteen-year follow-up of the Wisconsin sleep cohort. Sleep 2008; 31: 1071-1078.

155 Lévy P, Pépin JL, Tamisier R, et al. Outcomes of OSA and indications for different therapies. Eur Respir Monogr 2010; 50: 225-243.

156 Hunt SA, Abraham WT, Chin MH, et al. ACC/AHA 2005 Guideline Update for the Diagnosis and Management of Chronic Heart Failure in the Adult: a report of the American College of Cardiology/American Heart Association Task Force on Practice Guidelines (Writing Committee to Update the 2001 Guidelines for the Evaluation and Management of Heart Failure): developed in collaboration with the American College of Chest Physicians and the International Society for Heart and Lung Transplantation: endorsed by the Heart Rhythm Society. Circulation 2005; 112: e154-e235.

157 Jessup M, Brozena S. Heart failure. N Engl J Med 2003; 348: 2007-2018.

158 Javaheri S, Parker TJ, Liming JD, et al. Sleep apnea in 81 ambulatory male patients with stable heart failure. Types and their prevalences, consequences, and presentations. Circulation 1998; 97: 2154-2159.

159 Tremel F, Pepin JL, Veale D, et al. High prevalence and persistence of sleep apnoea in patients referred for acute left ventricular failure and medically treated over 2 months. Eur Heart J 1999; 20: 1201-1209.

160 Sin DD, Fitzgerald F, Parker JD, et al. Risk factors for central and obstructive sleep apnea in 450 men and women with congestive heart failure. Am J Respir Crit Care Med 1999; 160: 1101-1106.

161 Bradley TD, Logan AG, Kimoff RJ, et al. Continuous positive airway pressure for central sleep apnea and heart failure. $N$ Engl J Med 2005; 353: 2025-2033.

162 Schulz R, Blau A, Borgel J, et al. Sleep apnoea in heart failure. Eur Respir J 2007; 29: 1201-1205.

163 Oldenburg O, Lamp B, Faber L, et al. Sleep-disordered breathing in patients with symptomatic heart failure: a contemporary study of prevalence in and characteristics of 700 patients. Eur J Heart Fail 2007; 9: 251-257.

164 MacDonald M, Fang J, Pittman SD, et al. The current prevalence of sleep disordered breathing in congestive heart failure patients treated with beta-blockers. J Clin Sleep Med 2008; 4: 38-42.

165 Javaheri S, Caref EB, Chen E, et al. Sleep apnea testing and outcomes in a large cohort of medicare beneficiaries with newly diagnosed heart failure. Am J Respir Crit Care Med 2010; 183: 539-546.

166 Lévy P, Pépin J-L, Tamisier R, et al. Prevalence and impact of central sleep apnea in heart failure. Sleep Med Clin 2007; 2: 615-621.

167 Arzt M, Floras JS, Logan AG, et al. Suppression of central sleep apnea by continuous positive airway pressure and transplantfree survival in heart failure: a post hoc analysis of the Canadian Continuous Positive Airway Pressure for Patients with Central Sleep Apnea and Heart Failure Trial (CANPAP). Circulation 2007; 115: 3173-3180.

168 Sleep-related breathing disorders in adults: recommendations for syndrome definition and measurement techniques in clinical research. The Report of an American Academy of Sleep Medicine Task Force. Sleep 1999; 22: 667-689.

169 Nowbar S, Burkart KM, Gonzales R, et al. Obesity-associated hypoventilation in hospitalised patients: prevalence, effects, and outcome. Am J Med 2004; 116: 1-7. 
170 Berg G, Delaive K, Manfreda J, et al. The use of health-care resources in obesity-hypoventilation syndrome. Chest 2001; 120: 377-383.

171 Phipps PR, Starritt E, Caterson I, et al. Association of serum leptin with hypoventilation in human obesity. Thorax 2002; 57: 75-76.

172 Redolfi S, Corda L, La Piana G, et al. Long-term non-invasive ventilation increases chemosensitivity and leptin in obesityhypoventilation syndrome. Respir Med 2007; 101: 1191-1195.

173 Olson AL, Zwillich C. The obesity hypoventilation syndrome. Am J Med 2005; 118: 948-956.

174 Atwood CW. Sleep-related hypoventilation: the evolving role of leptin. Chest. 2005; 128: 1079-1081.

175 Yee BJ, Cheung J, Phipps P, et al. Treatment of obesity hypoventilation syndrome and serum leptin. Respiration 2006; 73: 209-212.

176 Campo A, Fruhbeck G, Zulueta JJ, et al. Hyperleptinemia, respiratory drive and hypercapnic response in obese patients. Eur Respir I 2007; 30: 223-231.

177 Chouri-Pontarollo N, Borel JC, Tamisier R, et al. Impaired objective daytime vigilance in obesity-hypoventilation syndrome: impact of noninvasive ventilation. Chest 2007; 131: 148-155.

178 Bixler EO, Vgontzas AN, Ten Have T, et al. Effects of age on sleep apnea in men: I. Prevalence and severity. Am J Respir Crit Care Med 1998; 157: 144-148.

179 Stoohs RA, Gingold J, Cohrs S, et al. Sleep-disordered breathing and systemic hypertension in the older male. J Am Geriatr Soc 1996; 44: 1295-1300.
180 Young T, Shahar E, Nieto FJ, et al. Predictors of sleep-disordered breathing in community-dwelling adults: the Sleep Heart Health Study. Arch Intern Med 2002; 162: 893-900.

181 Lavie P, Lavie L. Unexpected survival advantage in elderly people with moderate sleep apnoea. J Sleep Res 2009; 18: 397-403.

182 Ancoli-Israel S, Klauber MR, Kripke DF, et al. Sleep apnea in female patients in a nursing home. Increased risk of mortality. Chest 1989; 96: 1054-1058.

183 Campos-Rodriguez F, Martinez-Garcia MA, Durán-Cantolla J, et al. Cardiovascular mortality in females with obstructive sleep apnea. Effect of treatment with continuous positive airway pressure. Am J Respir Crit Care Med 2011; 183: A1056.

184 Gooneratne NS, Richards KC, Joffe M, et al. Sleep disordered breathing with excessive daytime sleepiness is a risk factor for mortality in older adults. Sleep 2011; 34: 435-442.

185 Levy P, Pepin JL, Malauzat D, et al. Is sleep apnea syndrome in the elderly a specific entity? Sleep 1996; 19: Suppl. 3, S29-S38.

186 Parish JM, Lyng PJ, Wisbey J. Compliance with CPAP in elderly patients with OSA. Sleep Med 2000; 1: 209-214.

187 Pelletier-Fleury N, Rakotonanahary D, Fleury B. The age and other factors in the evaluation of compliance with nasal continuous positive airway pressure for obstructive sleep apnea syndrome. A Cox's proportional hazard analysis. Sleep Med 2001; 2: 225-232.

188 Russo-Magno P, O'Brien A, Panciera T, et al. Compliance with CPAP therapy in older men with obstructive sleep apnea. J Am Geriatr Soc 2001; 49: 1205-1211. 